\title{
Novel dominant MPAN family with a complex genetic architecture as a basis for phenotypic variability
}

Peter Balicza, MD, PhD, Renata Bencsik, MSc, Andras Lengyel, MD, Aniko Gal, PhD, Zoltan Grosz, MD, Dora Csaban, MSc, Gabor Rudas, MD, PhD, Krisztina Danics, MD, PhD, Gabor G. Kovacs, MD, PhD, FRCPC, and Maria Judit Molnar, MD, PhD

Neurol Genet 2020;6:e515. doi:10.1212/NXG.0000000000000515

\section{Abstract}

\section{Objective}

Our aim was to study a Hungarian family with autosomal dominantly inherited neurodegeneration with brain iron accumulation (NBIA) with markedly different intrafamilial expressivity.

\section{Methods}

Targeted sequencing and multiplex ligation-dependent probe amplification (MLPA) of known NBIA-associated genes were performed in many affected and unaffected members of the family. In addition, a trio whole-genome sequencing was performed to find a potential explanation of phenotypic variability. Neuropathologic analysis was performed in a single affected family member.

\section{Results}

The clinical phenotype was characterized by 3 different syndromes -1 with rapidly progressive dystonia-parkinsonism with cognitive deterioration, 1 with mild parkinsonism associated with dementia, and 1 with predominantly psychiatric symptoms along with movement disorder. A heterozygous stop-gain variation in the C190rf12 gene segregated with the phenotype. Targeted sequencing of all known NBIA genes, and MLPA of PLA2G6 and PANK2 genes, as well as whole-genome sequencing in a trio from the family, revealed a unique constellation of oligogenic burden in 3 NBIA-associated genes (C19Orf12 p.Trp112Ter, CP p.Val105PhefsTer5, and PLA2G6 dup(ex14)). Neuropathologic analysis of a single case (39-year-old man) showed a complex pattern of alpha-synucleinopathy and tauopathy, both involving subcortical and cortical areas and the hippocampus.

\section{Conclusions}

Our study expands the number of cases reported with autosomal dominant mitochondrial membrane protein-associated neurodegeneration and emphasizes the complexity of the genetic architecture, which might contribute to intrafamilial phenotypic variability.

\author{
Correspondence \\ Dr. Balicza \\ balicza.peter@ \\ med.semmelweis-univ.hu
}




\section{Glossary}

APP $=$ amyloid precursor protein MLPA $=$ multiplex ligation-dependent probe amplification; MPAN $=$ mitochondrial membrane protein-associated neurodegeneration; NBIA = neurodegeneration with brain iron accumulation; WGS = wholegenome sequencing.

Neurodegeneration with brain iron accumulation (NBIA) is a group of rare, heterogeneous, hereditary neurodegenerative diseases in which excess iron accumulates in the basal ganglia and other vulnerable brain areas. ${ }^{1}$ At least 10 known genes are clearly associated with the condition ${ }^{2}: A T P 13 A 2$, C19Orf12, COASY, CP, DCAF17, FA2H, FTL, PANK2, PLA2G6, and WDR45. Clinical differentiation between different types of NBIAs is often very difficult because of the pleiotropy of the causative genes.

Mitochondrial membrane protein-associated neurodegeneration (MPAN) is a form of neurodegeneration with brain iron accumulation (NBIA-4; MIM614298) caused by pathogenic variants in the C19Orf12 gene. Although the study on the first family with MPAN reports it as an autosomal recessive condition, ${ }^{3}$ dominant inheritance of the disease was confirmed recently. ${ }^{4}$ Independent of the inheritance pattern, most MPAN cases are phenotypically similar at both clinical and neuropathologic levels. ${ }^{4}$

In this article, we report a novel large family with autosomal dominantly inherited NBIA associated with a segregating stop-gain variant in the C19Orf12 gene. Targeted sequencing and multiplex ligation-dependent probe amplification (MLPA) of other NBIA genes and whole-genome sequencing in a trio from the family revealed a unique constellation of oligogenic burden in 3 NBIA-associated genes. Neuropathologic analysis of a single case showed a complex pattern of alpha-synucleinopathy and tauopathy.

\section{Methods}

\section{Clinical evaluation}

Six members of the family (figure 1) (originating from Hungary) were examined by board-certified neurologists (A.L., P.B., M.J.M., and Z.G.) in the last 10 years at 2 academic centers (Debrecen and Budapest). For further 6 family members, medical documents from other centers and blood samples were available for this study. Brain MRIs, which are shown in this study, were performed on a 3T MRI, and the images were analyzed by a neuroradiologist (R.G.). This article presents a retrospective case study conducted with the approval from the institutional ethical committee. All participants provided informed written consent for the genetic studies.

\section{Genetic analysis}

Genetic investigations were performed from blood isolated with the Qiagen Blood Mini Kit. Sanger sequencing was performed for C19ORF12, CP, PANK2, PLA2G6, $C O A S Y$, and $B P A N$ genes. Whole-genome sequencing was

Figure 1 Family tree

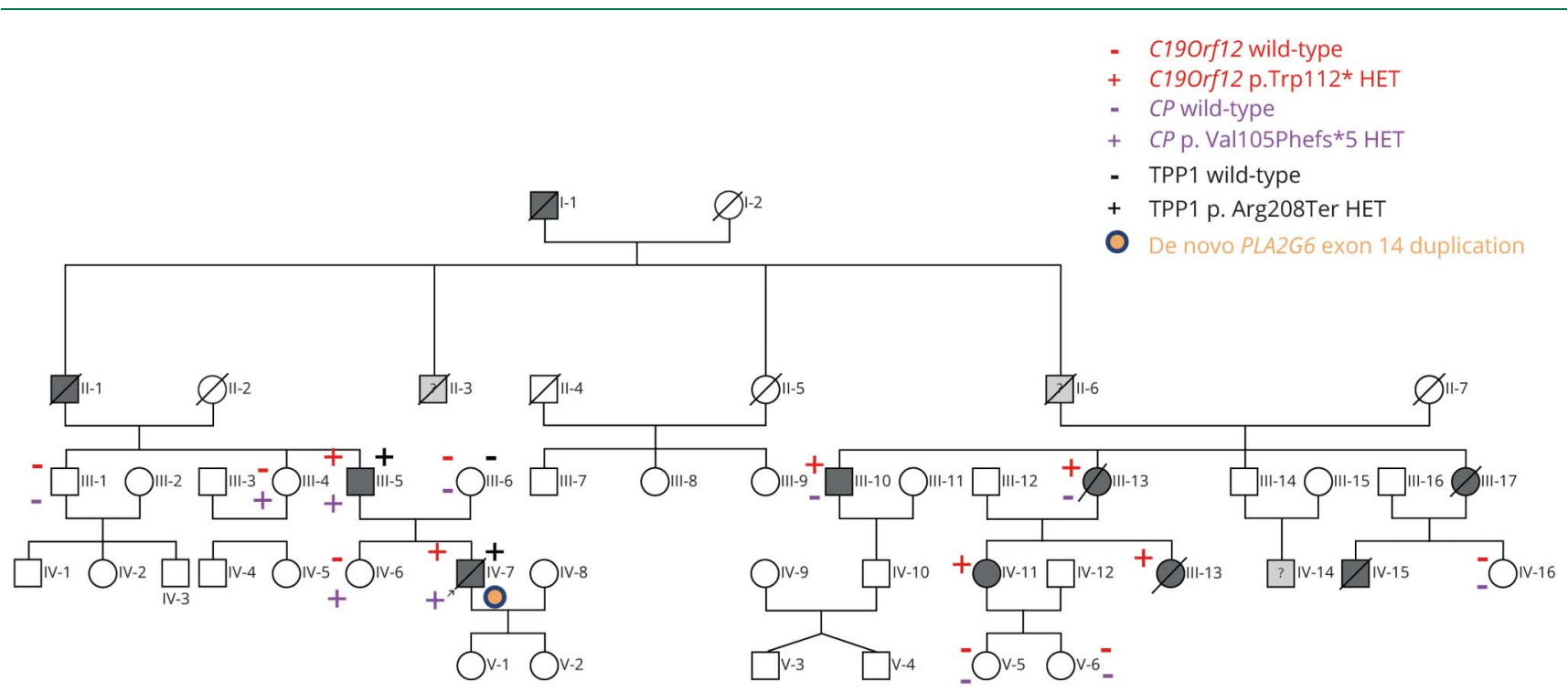

Genetically examined patients are marked on the family tree by a plus or minus sign, whereas color codes are used for different genetic variants. The index case is indicated with an arrow sign. Neurologic examinations performed by the authors were carried out in patients III/3, III/6, III/10, IV/7, IV/11, V/5, and V/6. 
performed in a trio at Novogene (en.novogene.com/), whereas data analysis from the whole-genome sequencing (WGS) was performed at the Institute of Genomic Medicine and Rare Disorders Semmelweis University (P.B.). Alignment was performed with Burrows-Wheeler Aligner (BWA-MEM), whereas variant calling was performed with the GATK haplotype caller. Multiple softwares were used for variant filtration, namely Genesis application (genesis-app.com), TGex (tgex.genecards.org), Moon software (diploid.com/moon) and the in-house software Variant-Analyzer. We also performed copy number variation call from the WGS data set using the CNVkit WGS method. MLPA was performed with the SALSA MLPA P120 probemix kit, which covers the PANK2 and PLA2G6 genes. The detailed filtration process is available in appendix e-1 (links.lww.com/NXG/A318).

\section{Neuropathology}

Formalin-fixed, paraffin-embedded tissue blocks were evaluated. In addition to hematoxylin and eosin and Luxol Fast Red staining, the following monoclonal antibodies were used for immunohistochemistry: anti-tau AT8 (pS202/ pT205, 1:200; Pierce Biotechnology, Rockford, IL), antiphospho-TDP-43 (pS409/410, 1:2,000; Cosmo Bio, Tokyo, Japan), anti-alpha-synuclein (1:2,000, clone 5G4; Roboscreen, Leipzig, Germany), anti-Abeta (1:50, clone 6F/3D; Dako, Glostrup, Denmark), and anti-amyloid precursor protein (APP, 1:8,000; Millipore, Burlington, $\mathrm{MA}$ ). The DAKO EnVision detection kit (peroxidase/DAB, rabbit/mouse) was used for visualization of antibody. Neuropathologic alterations in all examined anatomic regions were evaluated semiquantitatively (as none, mild, moderate, and severe).

\section{Data availability}

The data sets used and/or analyzed during the current study are available from the corresponding author on reasonable request.

\section{Results}

\section{Family history and clinical phenotype}

The family history showed an autosomal dominant pattern (figure 1). We have examined 6 members of the family and collected information and blood sample from 6 further family members. Three different clinical syndromes were observed (table):

First, rapidly progressive dystonia-parkinsonism with dementia was present in the index case (IV/7) and in patient IV/15. In the index case (IV/7), symptoms started around age 30 years, and he died at age 39 years. Wilson disease was first suspected in another center because serum ceruloplasmin and copper repeatedly decreased, but genetic testing of $A T P 7 B$ was negative, and MRI suggested iron accumulation in the basal ganglia. Because of the diagnostic uncertainty, liver biopsy was also performed earlier, which did not identify copper accumulation. Post hoc examination of the MRI also confirmed linear T2 hyperintensity at the medial medullary lamina of the globus pallidus. Examination at age 39 years detected severe parkinsonism, supranuclear vertical gaze palsy, generalized dystonia, severe dysphagia, widespread pyramidal tract signs, and dementia. At this late stage, ophthalmologic examination showed retinal dysfunction; however, optic atrophy was not described. Patient IV/15 presented with childhood-onset gait impairment and mental decline with initially slow progression and secondary rapid deterioration in his last 3 years. Parkinsonism was first appreciated at age 36 years. In the next year, rapid neurologic deterioration started, and at age 39 years, when he died of a concomitant pneumonia, severe dystonia-parkinsonism with dementia was present. Pathologic examination of the liver was normal. Genetic studies could not be performed from the available postmortem formalin-fixed paraffin-embedded brain samples because of pronounced DNA degradation. Brain neuropathology was partially reported earlier, ${ }^{5}$ which was expanded in this study after the genetic diagnosis was made in other family members.

Second, relatively mild, late-onset, slowly progressive parkinsonism and cognitive decline were present in the father of the index case (III/5) and his cousin (III/10).

Third, psychiatric symptoms along with mild movement disorder were observed in patient IV/11. She showed signs of mild disinhibition and abnormal results in the Luria test. Detailed neuropsychiatric examination detected mild frontotemporal cognitive decline. Fundus examination did not detect optic atrophy at age 46 years. Although her daughter (V/5) was diagnosed with schizophrenia, we do not attribute this to MPAN because genetic and MRI studies were negative. Reportedly, other female family members (patients III/13, III/17, and IV/13) had also predominant psychiatric symptoms.

\section{Brain MRI findings}

Brain MRIs (figure 2) revealed classical signs of brain iron accumulation; however, well-identifiable differences such as atypical iron accumulation in the caudate, together with cortical atrophy in patient III/10 and frontal atrophy in patient IV/1, have also been detected in different family members.

\section{Genetic analysis}

Sanger sequencing of PANK2, PLA2G6, CP, and C19Orf12 was performed in the index case (IV.7), which identified a heterozygous nonsense variant in the C19Orf12 gene (NM_ 001031726.3:c.335G>A; p.Trp112Ter) and a heterozygous deletion in the $C P$ gene, causing a frameshift (c.313delG, p.Val105Phefs ${ }^{*}$ ). WGS trio sequencing identified a further, heterozygous TPP1 stop-gain variant (NM_000391.4: c.622C $>\mathrm{T}$; p.Arg208Ter) inherited from the father, and 
Table Phenotype and genotype information of the family members

\begin{tabular}{|c|c|c|c|c|c|c|c|c|}
\hline Patient & $\begin{array}{l}\text { Examined } \\
\text { by us }\end{array}$ & Main symptoms & Age at onset, y & MRI & $\begin{array}{l}\text { C190rf12 } \\
\text { p.Trp112Ter }\end{array}$ & $\begin{array}{l}\text { CP } \\
\text { p.Val105PhefsTer5 }\end{array}$ & $\begin{array}{l}\text { TPP1 } \\
\text { p.Arg208Ter }\end{array}$ & $\begin{array}{l}\text { PLA2G6 } \\
\text { dup(ex14) }\end{array}$ \\
\hline III/1 & No & No symptoms & N/A & Not performed & Negative & Negative & Not tested & Not tested \\
\hline III/4 & No & No symptoms & N/A & Not performed & Negative & Positive & Not tested & Not tested \\
\hline III/5 & Yes & Mild parkinsonism $(\mathrm{MOCA}=27)$ & $\begin{array}{l}\text { Unknown (examined at } \\
\text { age } 63 \mathrm{y} \text { ) }\end{array}$ & Iron accumulation in the GP and SN & Positive & Positive & Positive & Negative \\
\hline III/6 & Yes & No symptoms & N/A & Not performed & Negative & Negative & Negative & Negative \\
\hline III/10 & Yes & $\begin{array}{l}\text { Mild parkinsonism and cognitive decline } \\
(\text { MOCA }=25)\end{array}$ & Late onset ( $\sim 60 \mathrm{y})$ & $\begin{array}{l}\text { Iron accumulation in the GP, } \\
\text { putamen, caudate nucleus, and SN }\end{array}$ & Positive & Negative & Not tested & Not tested \\
\hline III/13 & $\begin{array}{l}\text { No, } \\
\text { deceased }\end{array}$ & Psychiatric symptoms & Unknown & Reportedly positive & Positive & Negative & Not tested & Not tested \\
\hline III/17 & $\begin{array}{l}\text { No, } \\
\text { deceased }\end{array}$ & $\begin{array}{l}\text { Psychiatric symptoms (depression and } \\
\text { suicide) }\end{array}$ & Unknown & Unknown & Not tested & Not tested & Not tested & Not tested \\
\hline IV/6 & No & No symptoms & N/A & Not performed & Negative & Positive & Not tested & Not tested \\
\hline IV/7 & Yes & $\begin{array}{l}\text { Severe dystonia-parkinsonism and } \\
\text { dementia }\end{array}$ & Early onset ( 30 y) & $\begin{array}{l}\text { Iron accumulation in the GP and SN. } \\
\text { Hyperintense streak in the GP }\end{array}$ & Positive & Positive & Positive & Positive \\
\hline IV/11 & Yes & $\begin{array}{l}\text { Mild frontal lobe symptoms } \\
(\mathrm{MOCA}=28) \text { and dysdiadochokinesis }\end{array}$ & $\begin{array}{l}\text { Unknown (examined at } \\
\text { age } 46 \text { y) }\end{array}$ & $\begin{array}{l}\text { Iron accumulation in the GP and SN } \\
\text { and mild frontal atrophy }\end{array}$ & Positive & Not tested & Not tested & Not tested \\
\hline IV/13 & $\begin{array}{l}\text { No, } \\
\text { deceased }\end{array}$ & $\begin{array}{l}\text { Focal dystonia and psychiatric } \\
\text { symptoms }\end{array}$ & Unknown & Reportedly positive & Positive & Negative & Not tested & Not tested \\
\hline IV/15 & $\begin{array}{l}\text { No, } \\
\text { deceased }\end{array}$ & $\begin{array}{l}\text { Severe dystonia-parkinsonism and } \\
\text { dementia }\end{array}$ & Early onset $(\sim 12 \mathrm{y})$ & Reportedly positive & Not tested & Not tested & Not tested & Not tested \\
\hline IV/16 & No & No symptoms & N/A & Not performed & Negative & Negative & Not tested & Not tested \\
\hline V/5 & Yes & $\begin{array}{l}\text { Psychiatric (depression and delusions; } \\
\text { MOCA }=28 \text { ) }\end{array}$ & N/A & Negative & Negative & Negative & Not tested & Not tested \\
\hline V/6 & Yes & No symptoms & N/A & Negative & Negative & Negative & Not tested & Not tested \\
\hline
\end{tabular}

Abbreviations: GP = globus pallidus; MOCA = Montreal Cognitive Assessment; N/A = not applicable; SN = substantia nigra . 


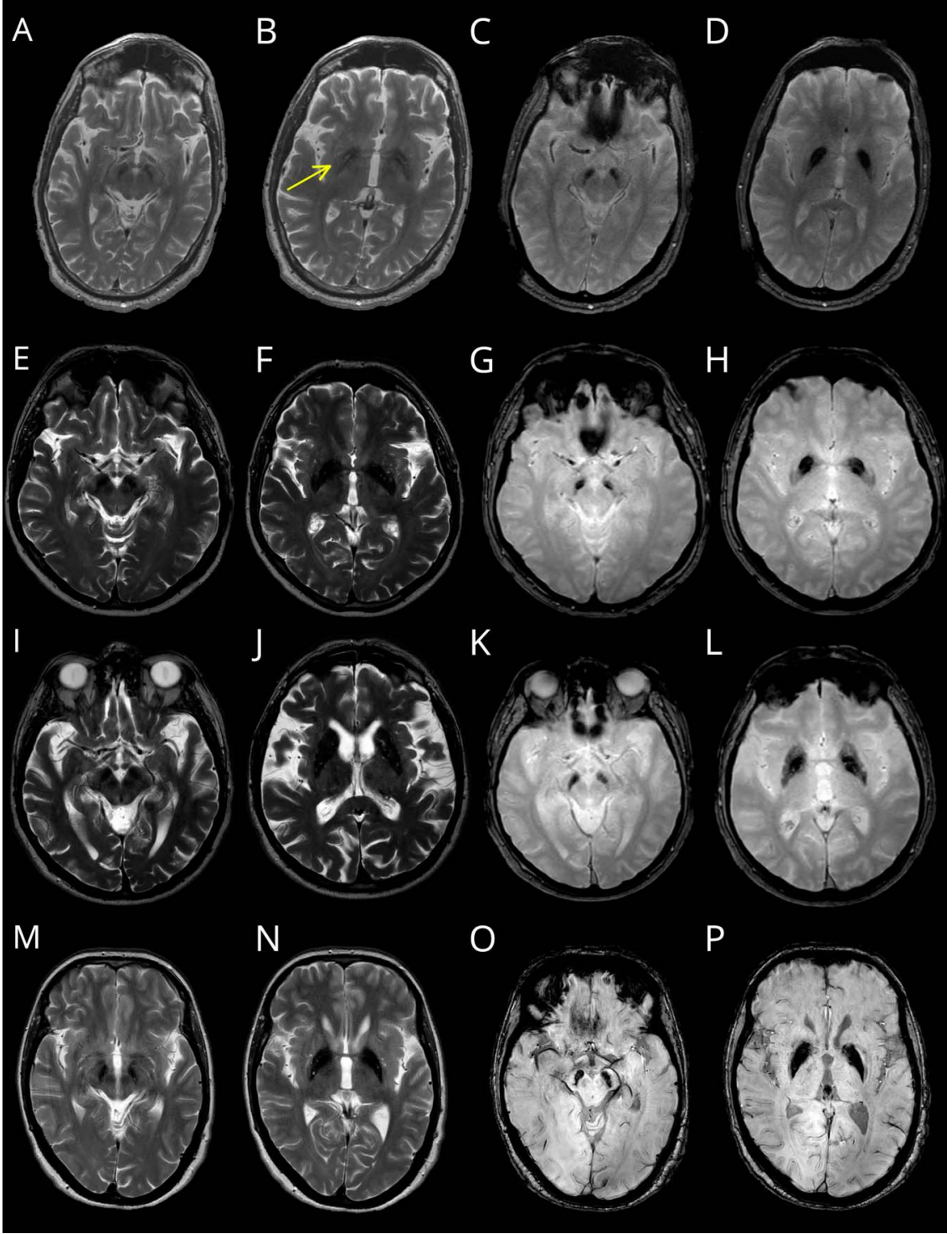

Brain MRIs of affected family members are depicted. Every row represents a single patient. (A-D) Patient IV/7. (E-H) Patient III/5. (I-L) Patient III/10. (M-P) Patient IV/11. In the first 2 columns, T2-weighted images of the brain at the level of the substantia nigra and at the level of the basal ganglia are represented. In the second 2 columns, iron-sensitive sequences are represented in the same level. Because MRIs were not performed at the same time point, $C$, $D, G$, and $H$ are $T 2 *$, whereas $K$ and $L$ are $T 2$-FFE. $O$ and $P$ are derived from susceptibilityweighted imaging sequences. All images show iron accumulation in the substantia nigra and globus pallidus internus. However, in patient III/ 10 (images I-L), iron accumulation is present in the head of the caudate also, and there is a marked global atrophy. In the index case, a linear hyperintense streaking, indicating internal medullary lamina of the globus pallidus, was also present (arrow in image B).
MLPA detected a de novo PLA2G6 exon duplication. Segregation analysis in 12 family members showed the MPAN variant to be segregating with the disease (figure 1).

\section{Neuropathology}

Neuropathologic examination was performed in patient IV/ 15 (figure 3). Neuronal loss and astrogliosis predominated in the temporal cortex, striatum, globus pallidus, and substantia nigra. Accumulation of Prussian-blue positivity was present in the globus pallidus. APP axonal spheroids predominated in the regions showing prominent neuronal loss, but they were noted in cortical areas as well. TDP-43 and $\beta$-amyloidpositive pathologic deposits were absent.

Alpha-synuclein pathology (figure 3, A-D) was characterized by neurites and spherical neuronal cytoplasmic deposits; however, on hematoxylin and eosin staining in the brainstem, they were not seen as unequivocal Lewy bodies. However, in the cortex, cortical Lewy body-like structures were identified. In all regions, extracellular spherical bodies were also immunostained by alpha-synuclein antibodies. The distribution of alpha-synuclein pathology was also most prominent in the basal ganglia; it was present also in the cortical areas and hippocampus. In the brainstem, neuronal inclusions were observed mostly in the substantia nigra. They were also observed in the dorsal vagus nucleus and as an unusual feature in the inferior olives but not in the locus coeruleus, where only neurites and spheroids were noted. Thus, the distribution of neuronal alpha-synuclein deposition was not exactly compatible with the Braak stages of Lewy pathology. ${ }^{6}$ Glial alphasynuclein pathology was not present.

Tau pathology (figure 3, E-H) was characterized by neuropil threads, neurites, diffuse neuronal cytoplasmic 
Figure 3 Neuropathologic features of an individual from this family (case IV/15)
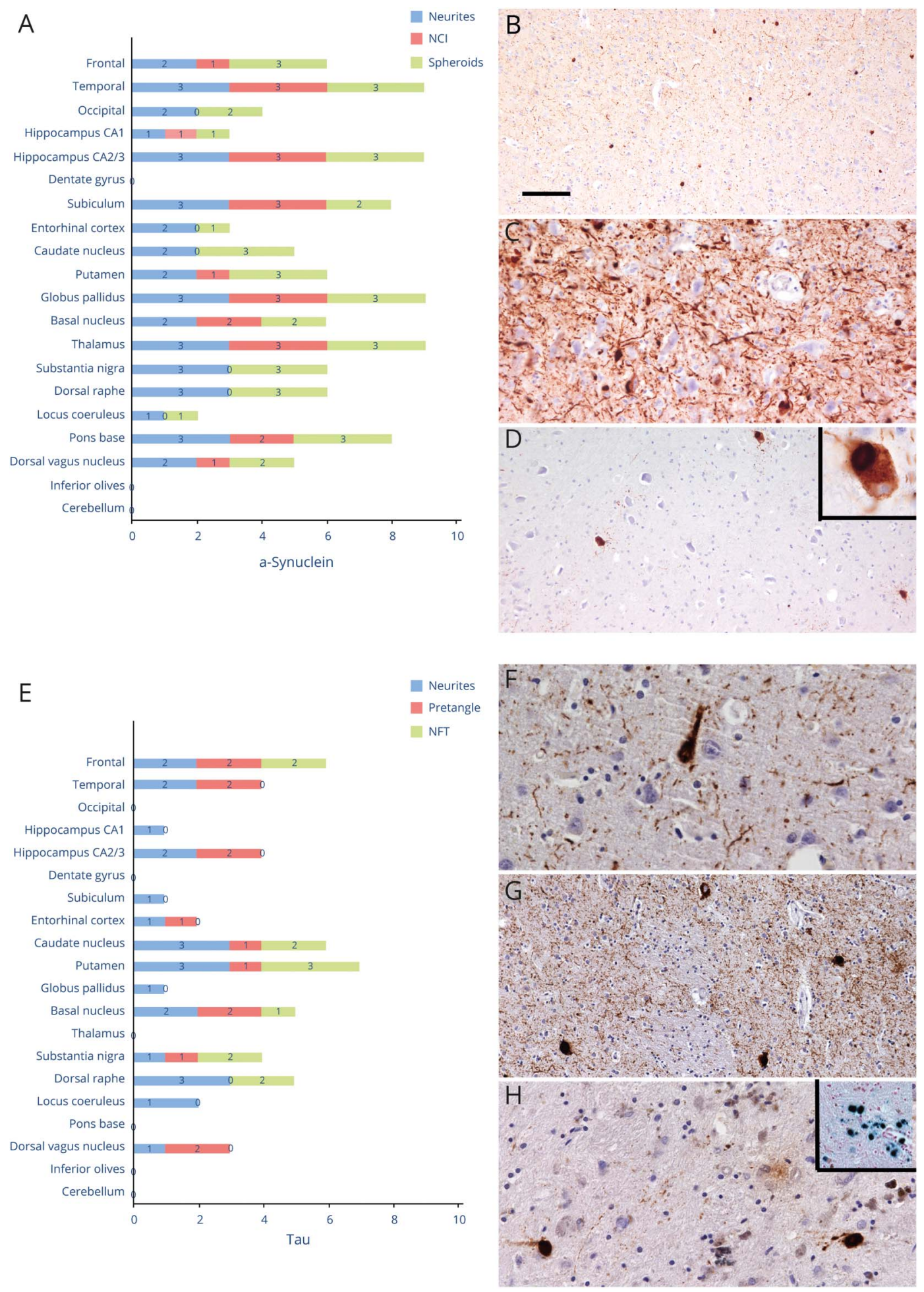

Anatomic mapping of alpha-synuclein-positive neurites, neuronal cytoplasmic inclusions ( $\mathrm{NCls}$ ), and spheroids (A). NCls and neurites in the temporal cortex (B) and the CA2/3 subregion of the hippocampus (C) and NCls in the inferior olives (D); the upper right inset shows an enlarged neuron. Anatomic mapping of tau-positive neurites, pretangles, and neurofibrillary tangles (NFTs) (E). NFT and neuropil threads/neurites in the frontal cortex (F), putamen (G), and globus pallidus $(\mathrm{H})$; in the globus pallidus iron accumulation as shown in the upper right inset with Prussian-blue staining.

positivity (pretangles), and less neurofibrillary tangles. The distribution of tau pathology did not follow the Braak and Braak stages ${ }^{7}$ and predominated the basal ganglia, substantia nigra, frontal and temporal cortex, and hippocampus. Glial tau pathology was not observed. 


\section{Discussion}

Our study serves as additional evidence for dominant inheritance for certain C19Orf12 variants, possibly through dominant negative effects. The detected C19Orf12 (heterozygous NM_001031726.3:c.335G>A; p.Trp112Ter) variant causes stop-gain at the same amino acid position as reported by Gregory et al. ${ }^{4}$ in a family with dominant inheritance. The variant detected in our study perfectly segregates with the phenotype in the 12 tested family members. Nonsensemediated decay is not predicted by the R package "masonmd"; thus, it is very likely that this is the most important pathogenic driver variant in this family. Clinical evidence, which also supports the diagnosis of MPAN, includes psychiatric manifestation in certain family members and the linear streaking ${ }^{9}$ on the MRI in the index patient. However, apparently no family member had axonal neuropathy. Marked intrafamiliar phenotypic heterogeneity was detected in this family; that is, certain family members have only mild parkinsonism, whereas others show severe and rapidly deteriorating dystonia-parkinsonism and dementia. Thus, in certain individuals or sporadic cases, heterozygous C19Orf12 variants may contribute to parkinsonism; however, this observation needs to be proven.

Why marked differences were observed in the expressivity of the disease still remained a question. The frameshift variant detected in the CP gene (NM_000096.4:c.313delG; p.Val105PhefsTer5) is missing from the population databases and can be classified as likely pathogenic according to the American College of Medical Genetics and Genomics guideline (evidence: PVS1, PM2). Pathogenic variants in the $C P$ genes associate with autosomal recessive cerebellar ataxia and aceruloplasminemia (MIM: 604290).$^{10}$ Although aceruloplasminemia is considered an autosomal recessive disease, many reports describe cerebellar ataxia in heterozygous carriers. ${ }^{11,12}$ In these patients, lower serum ceruloplasmin and copper levels are present, and MRI detects cerebellar atrophy. Although the index case had consistently low serum ceruloplasmin (between 0.08 and $0.11 \mathrm{~g} / \mathrm{L}$ ) and copper levels (between 5.8 and $9.0 \mu \mathrm{mol} / \mathrm{L}$ ), family members with mild symptoms and without symptoms were also carriers. Therefore, the effect of this variant is ambiguous.

MLPA detected a de novo PLA2G6 exon 14 duplication in the index case. PLA2G6 mutations are associated with a diverse clinical spectrum (PLA2G6-associated neurodegeneration; MIM: $256600 ; 610217 ; 612953)$. It is difficult to weight the effect of exon 14 duplication in our patient. According to Crompton et al., ${ }^{13}$ deletion/duplication events may account for up to $12.5 \%$ of PLA2G6 mutations, but whether single heterozygous mutations may lead to any symptoms is controversial. A single case report suggested that heterozygous PLA2G6 mutation might lead to Parkinson disease 14 (PARK14) ${ }^{14}$ Of interest, Lewy body pathology is also present in PLA2G6 associated neurodegeneration (PLAN).

The heterozygous TPP1 variant (NM_000391.4:c.622C>T; p.Arg208Ter) gained our attention because it is a stop-gain variation and a well-known pathogenic variant (ClinVarID: 2643) in neuronal ceroid lipofuscinosis (CLN2; MIM: 204500). ${ }^{15}$ It is a variant inherited from the father. CLN2 is an autosomal recessive disease with severe, progressive neurodegeneration, most commonly starting at age 2-4 years. Clinical symptoms include seizures, loss of speech, impaired psychomotor function, blindness, and premature death. In summary, it is less likely that this variant is directly connected to the phenotype of the described family.

Although the simultaneous presence of rare heterozygous variants on the same disease pathway raises the possibility of oligogenic inheritance in the background of differential expressivity, it is impossible to prove this in a single family. However, such findings are more frequently recognized with the use of next-generation sequencing, ${ }^{16}$ so this problem needs to be addressed in the future.

Altogether, there were only 4 autopsy reports from MPAN cases in the literature to date. ${ }^{3,4,17}$ To summarize the findings from these reports, widespread corticalsubcortical alpha-synuclein-positive Lewy pathology was present in both recessive and dominant cases with less pronounced tau pathology, mainly in the hippocampus. Neuropathologic examination of patient IV/15 was partially compatible with these reports; however, we identified some unusual features, most importantly, the pronounced tau pathology was unique in this case. Tau pathology was neuronal and was not compatible with that seen in primary tauopathies or Alzheimer disease. ${ }^{18}$ However, it is yet uncertain whether the widespread tau pathology is specific to MPAN. In addition, as an unusual feature, we detected neuronal cytoplasmic alpha-synuclein-positive inclusions in the inferior olives.

In this study, we report one of the largest MPAN families in the literature to date, confirming possible dominant inheritance of this disease. Neuropathologic study of a single family member showed widespread tau pathology beside the characteristic alpha-synucleinopathy. Although oligogenic inheritance was raised as a possibility in the background of differential expressivity, this hypothesis needs to be proven in systematic studies.

\section{Acknowledgment}

The authors thank the patients for their participation in this study. Several authors of this publication are members of the European Reference Network for Rare Neurological Diseases: Project ID No. 739510.

\section{Study funding}

Supported by the Hungarian Brain Research Program KTIA NAP_2017-1.2.1-NKP-2017-00002.

\section{Disclosure}

The authors report no disclosures. Go to Neurology.org/NG for full disclosures. 


\section{Publication history}

Received by Neurology: Genetics March 30, 2020. Accepted in final form July 27, 2020.

\section{Appendix Authors}

\begin{tabular}{|c|c|c|}
\hline Name & Location & Contribution \\
\hline $\begin{array}{l}\text { Peter } \\
\text { Balicza, MD, } \\
\text { PhD }\end{array}$ & $\begin{array}{l}\text { Institute of Genomic } \\
\text { Medicine, Budapest, } \\
\text { Hungary }\end{array}$ & $\begin{array}{l}\text { Patient examination, NGS data } \\
\text { analysis, and formulation of the } \\
\text { manuscript }\end{array}$ \\
\hline $\begin{array}{l}\text { Renata } \\
\text { Bencsik, MSc }\end{array}$ & $\begin{array}{l}\text { Institute of Genomic } \\
\text { Medicine, Budapest, } \\
\text { Hungary }\end{array}$ & $\begin{array}{l}\text { Performing NGS, Sanger } \\
\text { sequencing, and MLPA and } \\
\text { review of the manuscript }\end{array}$ \\
\hline $\begin{array}{l}\text { Andras } \\
\text { Lengyel, MD }\end{array}$ & $\begin{array}{l}\text { Motala Hospital, } \\
\text { Sweden }\end{array}$ & $\begin{array}{l}\text { Patient examination and } \\
\text { formulation of the manuscript }\end{array}$ \\
\hline $\begin{array}{l}\text { Aniko Gal, } \\
\text { PhD }\end{array}$ & $\begin{array}{l}\text { Institute of Genomic } \\
\text { Medicine, Budapest, } \\
\text { Hungary }\end{array}$ & $\begin{array}{l}\text { Performing Sanger sequencing } \\
\text { and MLPA and review of the } \\
\text { manuscript }\end{array}$ \\
\hline $\begin{array}{l}\text { Zoltan Grosz, } \\
\text { MD }\end{array}$ & $\begin{array}{l}\text { Institute of Genomic } \\
\text { Medicine, Budapest, } \\
\text { Hungary }\end{array}$ & $\begin{array}{l}\text { Patient examination and review } \\
\text { of the manuscript }\end{array}$ \\
\hline $\begin{array}{l}\text { Dora } \\
\text { Csaban, MSc }\end{array}$ & $\begin{array}{l}\text { Institute of Genomic } \\
\text { Medicine, Budapest, } \\
\text { Hungary }\end{array}$ & $\begin{array}{l}\text { Performing NGS and Sanger } \\
\text { sequencing and review of the } \\
\text { manuscript }\end{array}$ \\
\hline $\begin{array}{l}\text { Gabor } \\
\text { Rudas, MD, } \\
\text { PhD }\end{array}$ & $\begin{array}{l}\text { Chair of } \\
\text { Neuroradiology, } \\
\text { Department of } \\
\text { Radiology }\end{array}$ & $\begin{array}{l}\text { Evaluating the brain MRIs and } \\
\text { review of the manuscript }\end{array}$ \\
\hline $\begin{array}{l}\text { Krisztina } \\
\text { Danics, MD, } \\
\text { PhD }\end{array}$ & $\begin{array}{l}\text { Institute of Forensic } \\
\text { Medicine, Budapest, } \\
\text { Hungary }\end{array}$ & $\begin{array}{l}\text { Brain pathology analyses and } \\
\text { review of the manuscript }\end{array}$ \\
\hline $\begin{array}{l}\text { Gabor } \\
\text { Kovacs, MD, } \\
\text { PhD, FRCPC }\end{array}$ & $\begin{array}{l}\text { University of Toronto, } \\
\text { Canada }\end{array}$ & $\begin{array}{l}\text { Brain pathology analyses and } \\
\text { formulation of the manuscript }\end{array}$ \\
\hline $\begin{array}{l}\text { Maria Judit } \\
\text { Molnar, MD, } \\
\text { PhD }\end{array}$ & $\begin{array}{l}\text { Institute of Genomic } \\
\text { Medicine, Budapest, } \\
\text { Hungary }\end{array}$ & $\begin{array}{l}\text { Patient examination, data } \\
\text { analysis, and formulation of the } \\
\text { manuscript }\end{array}$ \\
\hline
\end{tabular}

\section{References}

1. Wiethoff $S$, Houlden H. Neurodegeneration with brain iron accumulation. In: Handbook of Clinical Neurology. Amsterdam, the Netherlands: Elsevier B.V.; 2018: 157-166.

2. Gregory A, Hayflick S. Neurodegeneration with brain iron accumulation disorders overview. In: GeneReviews [Internet]. Seattle, WA: University of Washington, Seattle; 1993.

3. Hogarth P, Gregory A, Kruer MC, et al. New NBIA subtype: genetic, clinical, pathologic, and radiographic features of MPAN. Neurology 2013;80:268-275.

4. Gregory A, Lotia M, Jeong SY, et al. Autosomal dominant mitochondrial membrane protein-associated neurodegeneration (MPAN). Mol Genet Genomic Med 2019;7: e00736.

5. Vincze A, Kapás I, Molnar MJ, Kovács GG. Clinicopathological variability in neurodegeneration with brain iron accumulation. Ideggyogy Sz 2010;63:129-135.

6. Braak H, Del Tredici K, Rüb U, De Vos RAI, Jansen Steur ENH, Braak E. Staging of brain pathology related to sporadic Parkinson's disease. Neurobiol Aging 2003;24: 197-211.

7. Braak H, Braak E. Neuropathological stageing of Alzheimer-related changes. Acta Neuropathol 1991;82:239-259.

8. $\mathrm{Hu} \mathrm{Z}$, Yau C, Ahmed AA. A pan-cancer genome-wide analysis reveals tumour dependencies by induction of nonsense-mediated decay. Nat Commun 2017;8 15943 .

9. Skowronska M, Kmiec T, Jurkiewicz E, Malczyk K, Kurkowska-Jastrzębska I, Czlonkowska A. Evolution and novel radiological changes of neurodegeneration associated with mutations in C19orf12. Parkinsonism Relat Disord 2017;39: $71-76$.

10. Marchi G, Busti F, Lira Zidanes A, Castagna A, Girelli D. Aceruloplasminemia: a severe neurodegenerative disorder deserving an early diagnosis. Front Neurosci 2019; $13: 325$.

11. McNeill A, Pandolfo M, Kuhn J, Shang H, Miyajima H. The neurological presentation of ceruloplasmin gene mutations. Eur Neurol 2008;60:200-205.

12. Borges MD, de Albuquerque DM, Lanaro C, Costa FF, Fertrin KY. Clinical relevance of heterozygosis for aceruloplasminemia. Am J Med Genet B Neuropsychiatr Genet 2019;180:266-271.

13. Crompton D, Rehal PK, MacPherson L, et al. Multiplex ligation-dependent probe amplification (MLPA) analysis is an effective tool for the detection of novel intragenic PLA2G6 mutations: implications for molecular diagnosis. Mol Genet Metab 2010; 100:207-212.

14. Ferese R, Scala S, Biagioni F, et al. Heterozygous PLA2G6 mutation leads to iron accumulation within basal ganglia and Parkinson's disease. Front Neurol 2018;9:536.

15. Nickel M, Simonati A, Jacoby D, et al. Disease characteristics and progression in patients with late-infantile neuronal ceroid lipofuscinosis type 2 (CLN2) disease: an observational cohort study. Lancet Child Adolesc Health 2018;2:582-590.

16. Keogh MJ, Wei W, Aryaman J, et al. Oligogenic genetic variation of neurodegenerative disease genes in 980 postmortem human brains. J Neurol Neurosurg Psychiatry 2018; 89:813-816.

17. Hartig MB, Iuso A, Haack $\mathrm{T}$, et al. Absence of an orphan mitochondrial protein, c19orf12, causes a distinct clinical subtype of neurodegeneration with brain iron accumulation. Am J Hum Genet 2011;89:543-550.

18. Kovacs GG. Invited review: neuropathology of tauopathies: principles and practice. Neuropathol Appl Neurobiol 2015;41:3-23. 


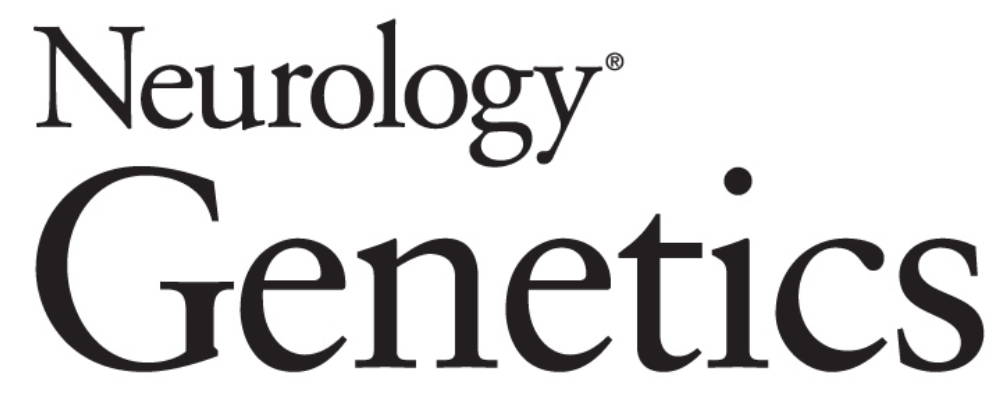

\section{Novel dominant MPAN family with a complex genetic architecture as a basis for phenotypic variability}

Peter Balicza, Renata Bencsik, Andras Lengyel, et al.

Neurol Genet 2020;6;

DOI 10.1212/NXG.0000000000000515

This information is current as of September 8, 2020

Updated Information \&

Services

References

Permissions \& Licensing

Reprints including high resolution figures, can be found at: http://ng.neurology.org/content/6/5/e515.full.html

This article cites 16 articles, 1 of which you can access for free at: http://ng.neurology.org/content/6/5/e515.full.html\#\#ref-list-1

Information about reproducing this article in parts (figures,tables) or in its entirety can be found online at:

http://ng.neurology.org/misc/about.xhtml\#permissions

Information about ordering reprints can be found online: http://ng.neurology.org/misc/addir.xhtml\#reprintsus

Neurol Genet is an official journal of the American Academy of Neurology. Published since April 2015, it is an open-access, online-only, continuous publication journal. Copyright Copyright ( 2020 The Author(s). Published by Wolters Kluwer Health, Inc. on behalf of the American Academy of Neurology.. All rights reserved. Online ISSN: 2376-7839.

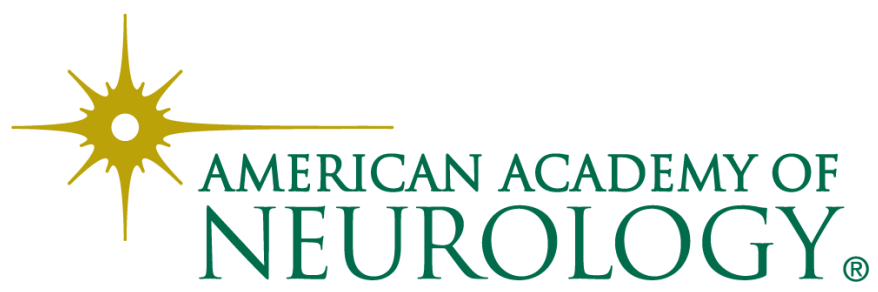

